Banco, Volume 1, Mei 2019

\title{
IMPLEMENTASI FATWA DSN-MUI NO: 86/ DSN-MUI/ XII/ 2012 TENTANG HADIAH DALAM PENGHIMPUNAN DANA
}

\author{
M. Ridwan Setiawan \\ M.ridwansetiawan46@gmail.com \\ Staff Mekanik Prima Motor Soreang Parepare \\ Rahmawati \\ IAIN Parepare \\ rahmawati@iainpare.ac.id \\ Wahidin \\ IAIN Parepare \\ wahidin@iainpare.ac.id
}

\section{Abstract}

The fatwa of the DSN-MUI is the answer issued by the National Sharia CouncilIndonesian Ulama Council (DSN-MUI) as an explanation of the sharia law for people who ask questions about problems in the field of Islamic economics. The goal is that sharia principles in the fatwa be implemented in contracts for Islamic Financial Institutions (LKS). However, public statements often arise that giving gifts to Islamic banks and conventional banks is the same as the scheme and method of giving. This study aims to see how the mechanism and suitability of DSN-MUI fatwa No: 86 / DSN-MUI / XII / 2012 concerning Prizes in Fundraising (Study at Bank Muamalat KCP Parepare). The results of the research can be stated that at Muamalat bank, KCP Parepare has two savings programs with prizes, the first is prizes with prizes, customers 


\section{Ridwan Setiawan, Rahmawati dan Wahidin}

deposit funds in the amount set by the bank for a predetermined period of time, second savings plan with prizes, customers deposit money at the beginning of the amount of money that has been determined by saving each month in the amount determined by the bank, the greater the amount of money saved the greater the number of prizes received. In the DSN-MUI fatwa related to the awarding of prizes there are 3 provisions related to this, namely the first provision related to prizes, the two provisions relating to the determination of receipt of implemented prizes according to fatwa, third not the provisions concerning prizes in deposits of Third Party Funds (DPK) all points in this fatwa implemented specifically on the third point that reads should not be the norm (habit, 'urf), that the' urf or custom prohibited by DSN-MUI in the fatwa prize aims to avoid changing intentions from the customer, intention to save become the desire to get something without effort.

\section{Keywords: Implementation, DSN-MUI fatwa, Prize mechanism}

\section{Abstrak}

Fatwa DSN-MUI adalah jawaban yang dikeluarkan oleh Dewan Syariah Nasional-Majelis Ulama Indonesia (DSN-MUI) sebagai penjelasan hukum syar'i bagi orang yang bertanya perihal masalah dalam bidang ekonomi syariah. Tujuannya agar prinsip-prinsip syariah dalam fatwa terimplementasi dalam akad-akad pada Lembaga Keuangan Syariah (LKS). Namun sering timbul pernyataan masyarakat bahwa pemberian hadiah pada bank syariah dan bank konvensional itu sama baik dari skema dan cara pemberiannya. Penelitian ini bertujuan untuk melihat bagaimana mekanisme dan kesesuaian fatwa DSN-MUI No: 86/ DSN-MUI/ XII/ 2012 Tentang Hadiah dalam Penghimpunan Dana (Studi pada Bank Muamalat KCP Parepare). Hasil penelitian dapat dikemukakan bahwa di bank Muamalat KCP Parepare meiliki dua program tabungan berhadiah, yang pertama tabungan prima berhadiah, nasabah mengendapkan dananya sebesar jumlah yang telah ditetapkan oleh bank selama jangka waktu yang telah ditentukan, yang kedua tabungan berencana berhadiah, nasabah menyetorkan uang diawal sebesar jumlah uang yang telah ditentukan dengan menabung tiap bulannya sebesar jumlah yang telah ditentukan oleh bank, semakin besar jumlah uang yang ditabung semakin besar pula jumlah hadiah yang diterima. Dalam fatwa DSN-MUI terkait tentang pemberian hadiah pada penghimpunan dana ada 3 ketentuan terkait hal tersebut yaitu pertama ketentuan terkait hadiah, kedua ketentuan terkait cara penentuan penerimaan hadiah sudah terimplementasi sesuai fatwa, ketiga pada ketentuan terkait hadiah dalam simpanan Dana Pihak Ketiga (DPK) tidak semua poin pada fatwa ini terimplementasi terkhusus pada poin ketiga yang berbunyi tidak boleh menjadi kelaziman (kebiasaan, 'urf), bahwasanya 'urf atau kelaziman yang dilarang oleh DSN-MUI dalam fatwa hadiah bertujuan untuk menghindari adanya niat yang berubah dari nasabah, niat dari menabung menjadi keinginan untuk mendapatkan sesuatu dengan tanpa adanya usaha. .

Kata kunci: Implementasi, fatwa DSN-MUI, Mekanisme pemberian Hadiah 


\section{A. Pendahuluan}

Seiring dengan perkembangan zaman, perbankan syariah di Indonesia sudah berkembang pesat, dimana bank-bank konvensional sudah membuka bank-bank unit yang berbasis syariah. Dengan berbagai produk-produk yang ditawarkan yang sesuai dengan kebutuhan pasar membuat calon nasabah bebas memilih produk yang ingin mereka gunakan sesuai dengan kebutuhan yang ingin mereka gunakan. Maksud dengan produk disini yaitu segala sesuatu yang bisa ditawarkan ke sebuah pasar dan bisa memuaskan sebuah keinginan atau kebutuhan. ${ }^{1}$

Produk dan fasilitas yang dikeluarkan oleh bank merupakan cara bank untuk menarik para konsumen untuk berinvestasi pada bank tersebut, Setiap produk yang dikeluarkan oleh perbankan suatu saat akan mengalami penurunan minat oleh konsumen, apabila sudah terjadi penurunan seperti itu maka bank perlu melakukan peningkatan yang dapat menunjang produk tersebut dengan memberikan suatu rangsangan berupa balas jasa yang akan diberikan oleh nasabahnya. Balas jasa tersebut dapat berupa bagi hasil, hadiah, pelayanan atau jasa lain yang menunjang dari produk tersebut.Transaksi atau kegiatan yang dilakukan oleh perbankan syariah tidak terlepas dari pengawasan Dewan Syariah Nasional dan setiap transaksi maupun kegiatan yang dilakukan bank harus berdasarkan prinsipprinsip syariah yang diatur didalam fatwa yang dikeluarkan oleh Dewan Syariah Nasional (DSN) dalam hal ini adalah Majelis Ulama Indonesia(MUI).

Berdasarkan Undang-Undang No. 21 Tahun 2008 tentang Perbankan Syariah, ditetapkan bahwa bank-bank syariah Indonesia, yang terdiri atas bank yang sepenuhnya melaksanakan kegiatan usahanya berdasarkan prinsip syariah dan bank konvensional yang melaksanakan kegiatan usahanya berdasarkan prinsip syariah melalui Unit Usaha Syariah (UUS) yang dimilikinya, tidak boleh melakukan kegiatan usaha yang melanggar prinsip syariah. Prinsip syariah yang harus dipatuhi oleh bank-bank syariah menurut Undang-Undang Perbankan Syariah adalah prinsip syariah yang telah difatwakan oleh Dewan Syariah Nasional - Majelis Ulama Indonesia dan selanjutnya telah dituangkan dalam Peraturan Bank Indonesia. ${ }^{2}$

Namun dalam perkembangannya, perbankan syariah tidak hanya memiliki peluang melainkan juga berbagai permasalahan. Berbicara problematika perbankan syariah dilihat dari sisi promosi (pemberian bonus atau pemberian hadiah), yang termasuk strategi pemasaran seharusnyadiaplikasikan secara profesional menurut prinsip syariah, namun demikian skema terlihat pengaplikasiannya di bank syariah seperti promosi alaperbankan konvesional. Sehingga timbul perdebatan di kalangan ulama dan akademisi terkait strategi pemeberian hadiah, apalagi kemudian strategi semacam ini dikuatkan dengan fatwa DSN-

1http://id.m.Wikipedia.org / wiki/produk (20 April 2017)

2 Sutan Remy Sjahdeini, Perbankan Syariah (Jakarta: PT Adhitya Andrebina Agung, 2014), h. 2. 


\section{Ridwan Setiawan, Rahmawati dan Wahidin}

MUI No. 86/DSN-MUI/ XII / 2012 Tentang Hadiah Dalam Penghimpunan Dana Lembaga Keuangan Syariah, yang kemudian setelah diteliti fatwa ini membuka pintu gebrakan baru bagi problem strategi pemberian hadiah, namum demikian, meski dengan adanya fatwa ini justru membuka celah bagi pihak bank syariah untuk mencari cara bagaimana bisa menandingi strategi bank konvesioanal dalam pemberian hadiah pada akad penghimpunan dana.

Adapun fatwa yang menjadi landasan dalam praktik pemberian hadiah dalam produk penghimpunan dana perbankan syariah bukan berarti praktik tersebut tidak lagi dipertentangkan,justru terdapat beberapa masalah yang saat ini menjadi perhatian beberapa ulama, para ekonomi islam serta kalangan akademisi, dilihat dari fatwa dan modifikasi produk perbankan syariah yang telah memberikan ketentuan dalam praktik pemberian hadiah, namun demikian dalam pengimplementasiannya terdapat kesamaan dengan konvensional. Sekedar perbandingan, dalam bank konvensional akad yang digunakan dalam giro adalah simpanan dengan bunga, sementara pada akad yang digunakan dalam giro wadiah atau giro mudharabah dengan hadiah. Begitupun halnya dengan tabungan wadi'ah dan tabungan mudharabah. Karena itu, kontruksi hadiah dan bunga terlihat sama sekalipun dengan perbedaan istilah.

Melihat dari permasalahan diatas mengenai permaslahan tentang pemberian hadiah, peneliti menemukan praktik pemberian hadiah di bank Muamalat KCP Parepare dalam menarik nasabah untuk menghimpun dananya, sehingga peneliti melihat bahwa perlu pendeskripsian apakah bank Muamalat KCP Parepare sudah menerapkan terkait pemberian hadiah dalam penghimpunan dana di bank syariah menurut Fatwa DSN-MUI No. 86/DSNMUI/XII/2012 tentang pemberian hadiah. Agar masyarakat lebih jelas danbenarbenarmengetahui bagaimana tentang pemberian hadiah dibank syariah dengan merujuk pada fatwa DSN-MUI No. 86/DSN-MUI/XII/2012 sehingga, demikianPeneliti akan mengkaji masalah diatas dalam rumusan masalah sebagai berikut.

\section{B. Diskusi dan Pembahasan}

\section{Gambaran Umum dan Profil Penelitian}

PT. Bank Muamalat Indonesia Tbk KCP Parepare merupakan lembaga keuangan yang lokasinya sangat strategis dan mudah dijangkau oleh masyarakat yaitu yang beralamat di Jl. Sultan Hasanuddin ruko 3 Parepare yang bergerak dalam bidang usaha perbankan syariah, yang selalu memberikan berbagai macam produk kepada masyarakat baik dalam bentuk kredit maupun dalam bentuk tabungan untuk investasi, guna untuk mendatangkan kemaslahatan diantara keduanya (mud $\left\{a>\right.$ rib dan $S_{a}>$ bibul ma $>$ ).

a. Visi Misi Bank Muamlat Indonesia

- Visi

Menjadi Bank Syariah terbaik dan termasuk dalam 10 besar bank di Indonesia dengan eksistensi yang diakui di tingkat regional.

- Misi 
Membangun lembaga keuangan syariah yang unggul dan berkesinambungan dengan penekanan pada semangat kewirausahaan berdasarkan prinsip kehatihatian, keunggulan sumber daya manusia yang islami dan professional serta orientasi investasi yang inovatif, untuk memaksimalkan nilai kepada seluruh pemangku kepentingan. ${ }^{3}$

b. Sejarah Bank Muamalat Indonesia

Ide konkrit pendirian Bank Mualat Indonesia berawal dari loka karya "Bunga Bank dan Perbankan" yang diselenggarakan Majelis Ulama Indonesia (MUI) pada tanggal 18-20 Agustus 1990 di Cisarua. Ide ini kemudian lebih dipertegas lagi dalam Musyarawah Nasional ( MUNAS ) ke IV MUI di Hotel Sahid Jaya Jaakarta Tanggal 22-25 Agustus 1990 yang mengamanahkan kepada Bapak K.H. Hasan Bahri yang terpilih kembali sebagai Ketua Umum MUI, untuk merealisasikan pendirian Bank Islam tersebut. Setelah itu, MUImembentuk suatu Kelompok Kerja ( POKJA ) untuk mempersiapkan segala sesuatunya. Tim POKJA ini membentuk Tim Kecil “ Penyiapan Buku Panduan Bank Tanpa Bunga “, yang iketahui Bapak Dr. Ir. M. Amin Azis.

Hal paling utama dilakukan oleh Tim MUI ini disamping melakukan pendekatan pendekatan dan konsultasi dengan pihak - pihak terkait adalah menyelenggarakan pelatihan calon staf melalui Management Development Program ( MDP) di Lembaga Pendidikan Perbankan Indonesia ( LPPI ), Jakarta yang dibuka pada tanggal 20 Maret 1991 oleh Menteri Muda Keuangan, dan meyakinkan beberapa pengusaha muslim untuk jadi pemegang saham pendiri. Untuk membantu kelancaran tugas - tugas MUI ini dibentuklah Tim Hukum Ikatancendekiawan Muslim Indonesia ( ICMI ) yang dibawah Ketua Drs. Karnaen Perwaat Madja, MPA. Tim ini bertugas untuk mempersiapkan segala sesuatu yang menyangkut aspek hukum Bank Islam.

Pada tanggal 1 November 1991 terlaksana penandatanganan Akta Pendirian PT. Bank Muamalat Indonesia di Sahid Jaya Hotel dihadapan Notaris Yudo Paripurno, SH. Dengan Akte Notaris no. 1 tanggal 1 November 1991 ( IZIN MENTERI KEHAKIMAN NO. C2.2413.HT.01.01 ). Pada saat penandatanganan Akte Pendirian ini terkumpul komitmen pembelian saham sebanyak Rp 48 Miliar. Selanjutnya, pada acara silaturahmi pendirian Bank Syariah di Istana Bogor, diperoleh tambahan komitmen dari masyarakat Jawa Barat yang turut menanam modal senilai Rp106 M. dengan angka modal awal ini Bank akte notaris no. 1 tanggal 1 novemberMuamalat mulai beroperasi pada tanggal 1 Mei 1992 bertepatan dengan tanggal 27 Syawal $1412 \mathrm{H}$, SK Menteri Keuangan RI No. 1223/MK. 013/1991 tanggal 15 November 1991 diikuti oleh izin usaha keputusan MenKeu RI No. 430/KMK.013/1992 tanggal 24 April 1992. Pada hari jum'at, 27 Syawal 1412 H, bertepatan dengan tanggal 1 Mei 1992, Menteri Keuangan dan

3http://www.bankmuamalat.co.id/ (21 Mei 2018) 


\section{Ridwan Setiawan, Rahmawati dan Wahidin}

dengan dihadiri oleh Gubernur Bank Indonesia,meresmikan mulai beroperasinya Bank Muamalat dalam upacara “ Soft Opening “ yang ada di Kantor Pusat Bank Muamalat Di Gedung Arthaloka, Jl. Jend. Sudirman Kav, 2 Jakarta.

Pada tanggal 27 Oktober 1994, Bank Muamalat berhasil menyandang predikat sebaga Bank Devisa yang semakin memperkokoh posisi perseroan sebagai Bank Syariah pertama dan terkemuka di Indonesia dengan beragam jasa maupun produk yang terus dikembangkan. Pada saat Indonesia dilanda krisis moneter, sector perbankan nasional tergulung oleh kredit macet disegmen korporasi. Bank Muamalat pun terimbas dampak krisis. Pada tahun 1998, perseroan mencatat rugi sebesar Rp 105 M.

Dalam upayah memperkuat permodalannya, Bank Muamalat mencari permodalan yang potensial, dan ditanggapi secara positif oleh Islamic Development Bank ( IDB ) yang berkedudukan di Jeddah, Arab Saudi. Pada RUPS tanggal 21 Juni 1999 IDB secara resmi menjadi salah satu pemegang saham Bank nuamalat. Oleh karenanya, kurun waktu antara tahun 1999 sampai 2000 merupakan ma sa masa yangpenuh tantangan sekaligus keberhasilan bagi Bank Muamalat karena berhasil membalikkan kondisi dari rugi menjadi laba dari upaya dan dedikasi setiap pegawai Muamalat, ditunjang oleh kepemimpinan yang kuat,strategi pengembangan usaha yang tepat,serta ketaatan terhadap pelaksanaan perbankan Syari'ah secara murni.

Saat ini bank muamalat telah memberikan layanan bagi lebih dari 2.5juta nasabah melalui 275 gerai yang tersebar di 33 provinsi Indonesia, dan didukung dengan jaringan ATM sebanyak 32.00 dan 95.000 merchant debet. Selain di Indonesia, PT BMI telah membuka cabang di Negara Malaysia yang dijalankan dengan jaringan Malaysia Electroinic Payment System (MEPS), sehingga dapat diakses di lebihdari 2000 ATM yang tersebar di seluruh Malaysia. Selain itu dengan berbagai prestasi yang diterima selama ini semakin memacu Bank Muamalat untuk memberikan pelayanan yang terbaik agar dapat lebih menjangkau seluruh masyarakat Indoensia. Salah satu prestasi yang diterima oleh Bank Muamalat yaitu Best Islamic Retail Bank dan Best Islamic Bank in Indonesia dari Islamic Finance News (IFN) di Malaysia pada 9 Maret 2015 lalu. ${ }^{4}$

c. Struktur Organisasi

4https://www.scribd.com/doc/84097240/Gambaran-Umum-Bank-Muamalat-Indonesia (21 Mei 2018) 


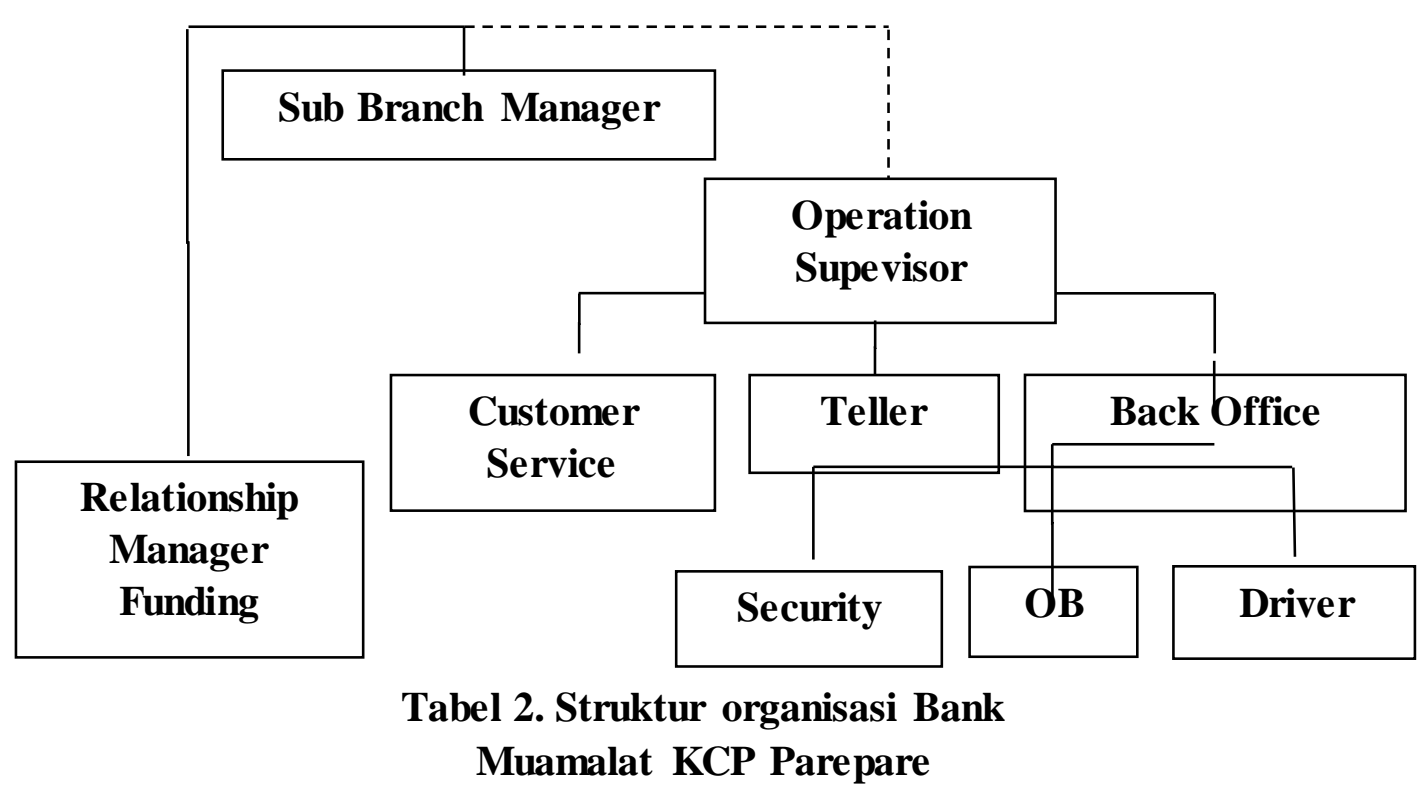

d. Ruang Lingkup Wewenang dan Mekanisme

Pada dasarnya setiap organisasi harus mempunyai job description yang jelas dan mudah dipahami oleh setiap unit kerja masing-masing, supaya tugas dan tanggung jawab masing-masing unit dapat direncanakan, dikendalikan dan diawasi dengan baik. Adapun tugas, tanggung jawab dan wewenang masing-masing jabatan di bank Muamalat adalah sebagai berikut :

1) Sub Branch Manager

\section{Tugas :}

Bertanggung jawab untuk merencanakan dan mengkoordinir, mengelola, dan mensupervisi kegiatan kantor cabang pembantu yang meliputi kegiatan operasional dan pemasaran sesuai dengan peraturan yang ditetapkan untuk mendapatkan keuntungan yang maksimal.

Tanggung Jawab :

Merupakan penanggung jawab semua kegiatan keuangan dan perbankan pada kantornya, dan juga menandatangani berkas nasabah yang mengajukan kredit yang telah disetujui sebelumnya.

Wewenang :

a) Selaku Pemimpin tertinggi di Kantor Cabang mengkoordinir seluruh kegiatan agar terarah dan mencapai target yang telah ditetapkan. 


\section{Ridwan Setiawan, Rahmawati dan Wahidin}

b) Berhak memberikan teguran, kritik terhadap Karyawan/Staf dalam rangka memacu kreatifitas dan membentuk etos kerja yang baik dan professional.

2) Operation Supervisor Tugas, Tanggung Jawab, dan Wewenang:

Merencanakan, mengelola, mengawasi (mensupervisi) kegiatan kantor yang meliputi kegiatan operasional dan pengembangan kantor cabang pembantu. Operation Supervisior juga mengautorisasi (mengsahkan) transaksi-transaksi serta dokumen-dokumen Bank Muamalat.Wewenang seorang Operation Supervisior adalah memegang kunci dan membuka pintu khasanah.

3) Teller

Tugas :

a) Mengatur dan menyiapkan pengeluaran uang tunai yang telah disetujui oleh kepala cabang.

b) Membuat mutasi harian atau laporan kas harian.

Tanggung Jawab :

Pengambilan teller's box dari khasanah utama, pembukaan kas, transaksitransaksi teller, mutasi uang tunai antar teller, proses akhir hari kerja, selisih pembulatan, dan penutupan kas.

4) Customer Service

Tugas Dan Tanggung Jawab:

a) Memberikan penjelasan kepada nasabah mengenai produk Bank Muamalat.

b) Melayani nasabah saat pembukaan dan penutupan rekening (filling document).

c) Menginput data base nasabah lalu memverifikasi dan autentikasi dokumen.

d) Melayani pertanyaan ataupun keluhan dari nasabah baik yang langsung datang ke kantor maupun memalui telepon.

e) Melaksanakan kegiatan service counter antara lain informasi saldo.

f) Menjaga current file nasabah (Giro, Tabungan dan Deposito).

5) Back Office

Tugas, Tanggung Jawab dan Wewenang:

a) Menginput seluruh transaksi operasional bank ke dalam komputer.

b) Menerima kiriman dan paket dari luar dan mengatur pengalokasiannya.

c) Mengawasi dan mencatat penggunaan peralatan dan perlengkapan kantor.

6) Marketing Staff

Tugas dan tanggung jawab Relationship Manager Funding:

a) Merancang dan mengaplikasikan strategi bisnis penghimpunan dana.

b) Memperkenalkan dan menawarkan produk kepada masyarakat.

c) Bertanggung jawab atas pencapaian target penghimpunan dana.

Tugas dan tanggung jawab Relationship Manager Consumer:

d) Menganalisis calon nasabah pembiayaan.

e) Memproses, mengelola, dan mempersiapkan berkas nasabah pembiayaan. 
f) Bertanggung jawab atas pencapaian target pembiayaan.

\section{Sistem Pemberian Hadiah pada Bank Muamalat KCP Parepare}

Dalam sistem pemberian hadiah dalam bank Muamlat KCP Parepare merupakan cara bank untuk menambah loyalitas nasabah dan untuk menambah disertifikasi produk, dan dalam penerimaan hadiah yang diberikan oleh bank Muamlat tidak diundi tetapi deberikan secara langsung. Sebagai mana yang dijelaskan oleh Rahmat Ali bahwa:

Tujuan bank Muamlat mengadakan sistem pemberian hadiah ini untuk menambah loyalitas nasabah dan untuk diversifikasi produk untuk nasabah, program ini juga sifatnya unik dan jarang ditemui di bank-bank lain karena pemberian hadiahnya secara langsung tidak diundi. ${ }^{5}$

a. Dalam sistem pemberian hadiah pada bank Muamalat KCP Parepare nasabah harus membuka tabungan, pemberian hadiahnya dalam bentuk produk tabungan yang dimana produk tabungan tersebut ada dua macam di antaranya :

1) Tabungan Prima Berhadiah

Tabungan Muamalat Prima iB dipersembahkan bagi anda yang mendambakan hasil maksimal dan kebebasan bertransaksi. Nasabah akan mendapatkan keuntungan berupa kenyamangan bertransaksi kapan saja dan dimana saja melalui E - Banking Muamalat ( ATM, Internet Banking, Mobile Banking dan Phone Banking ).

a) Nasabah Perorangan

Syarat untuk membuka tabungan secara perorangan:

- Mengisi formulir pembukaan rekening

- Kartu identitas:

○ WNI: KTP / SIM / Paspor yang masih berlaku dan NPWP/Surat pernyataan

- WNA:KITAS/KIMS/Paspor/Surat referensi

b) Sedangkan untuk non perorangan:

- Mengisi formulir pembukaan rekening

- Dokumen yang diperlukan:

- NPWP

- Akta Pendirian dan Perubahan (jika ada)

- Izin usaha yaitu TDP dan SIUP bagi badan usaha

- Surat kuasa penunjukkan pengelolaan rekening

- Bukti identitas diri penerima dan pemberi kuasa

c) Cara Pemberian Hadiah pada Tabungan Prima Berhadiah

Nasabah berhak memilih hadiah berupa televisi, smartphone, logam mulia dan kendaraan baik itu motor maupun mobil, untuk mendapatkan hadiah melalui

${ }_{5}^{5}$ Rahmat Ali, pimpinan Bank Muamalat KCP Parepare, kec. Ujung kota Parepare, Sulsel, wawancara oleh penulis di Parepare, 1 Mei 2018. 


\section{Ridwan Setiawan, Rahmawati dan Wahidin}

tabungan muamalat prima syaratnya anda harus menabung minimal Rp25 juta selama minimal 5 tahun.

Dan jika nasabah menabung Rp25 juta selama 5 tahun maka anda bebas memilih hadiahnya mulai dari televisi, AC dan logam mulia. Semakin lama dan semakin besar uang yang di tabung maka semakin besar juga hadiah yang bisa didapatkan seperti hadiah langsung berupa sepeda motor. Untuk mendapatkan hadiah sepeda motor anda harus menabung uang sebanyak Rp92.500.000 selama 5 tahun, dan jika menabung Rp1.594.000.000 juta selama 5 tahun maka anda berhak mendapatkan hadiah 1 unit mobil.

Jadi inti dari pemberian hadiah pada tabungan prima berhadiah ini nasabah menyetorkan uangnya sebesar jumlah yang telah ditetapkan oleh bank selama jangka waktu yang telah ditentukan oleh bank, semakin besar dana yang nasabah tabungkan semakin besar pula hadiah yang diterima oleh nasabah. Dijelaskan oleh Rahmat Ali bahwa:

Pada tabungan prima berhadiah ini nasabah hanya mengendapkan dananya selama jangka waktu yang telah ditentukan oleh bank dan disetujui oleh nasabah. ${ }^{6}$ Selain mendapatkan hadiah-hadiah yang ditawarkan, nasabah yang membuka rekening di tabungan muamalat prima berhadiah juga bebas biaya administrasi dan tetap akan mendapatkan keuntungan berupa bagi hasil setiap bulannya dan jika saldo tabungan semakin besar maka bagi hasil yang akan anda terima juga semakin besar.

\section{2) Tabungan Berencana Berhadiah}

Rencana dan impian di masa depan memerlukan keputusan perencanaan keuangan yang dilakukan saat ini, seperti perencanaan pendidikan, pernikahan, perjalanan ibadah/wisata, uang muka rumah/kendaraan, berkurban saat Idul Adha, perpanjangan STNK/pajak kendaraan, persiapan pensiun/hari tua, serta rencana atau impian lainnya. Tabungan iB Muamalat Rencana adalah solusi perencanaan keuangan yang tepat untuk mewujudkan rencana dan impian di masa depan dengan lebih baik sesuai prinsip syariah.

a) Persyaratan Kepesertaan

- Usia saat pembukaan rekening minimal 17 tahun, maksimal 60 tahun

- Usia pada saat tabungan Muamalat Rencana iB jatuh tempo maksimal 65 tahun.

- Memiliki rekening Tabungan Muamalat iB sebagai rekening sumber dana nasabah.

${ }^{6}$ Rahmat Ali, pimpinan Bank Muamalat KCP Parepare, kec. Ujung kota Parepare, Sulsel, wawancara oleh penulis di Parepare, 1 Mei 2018. 
b) Penutupan Rekening :

- Otomatis saat telah jatuh tempo.

- Apabila gagal debet setoran selama 3 bulan berturut-turut.

- Atas permintaan Nasabah.

- Apabila saldo hasil klaim nasabah telah dikreditkan ke rekening sumber dana nasabah

c) Keunggulan Tabungan Muamalat Rencana iB :

- Setoran minimal Rp 100.000 dengan jangka waktu 24 bulan sampai 120 bulan

- Fasilitas autodebit gratis, secara otomatis memindahkan dana setoran bulanan dari rekening sumber dana

- Saldo Tabungan Muamalat Rencana iB otomatis dipindahkanbukukan ke rekening sumber dana saat jatuh tempo

- Nisbah yang kompetitif sebesar 30\%

- Bebas biaya administrasi bulanan

- Nasabah mendapat perlindungan asuransi jiwa secara gratis tanpa perlu melakukan medical check-up, biaya premi ditanggung oleh Bank Muamalat.

d) Cara Pemberian Hadiah pada Tabungan Berencana Berhadiah

Nasabah berhak memilih hadiah berupa tv, laptop, smartphone, logam mulia dan kendaraan baik itu motor maupun mobil, untuk mendapatkan hadiah melalui tabungan muamala berencana berhadiah syaratnya anda haru menyetorkan uang diawal minimal Rp. 4.150 .000 dan maksimal Rp. 606.200.000 dengan menabung minimal Rp.100 ribu sampai dengan Rp. 549.500 .000 dengan jangka waktu mulai dari 2 tahun hingga 10 tahun.

Dan jika nasabah menyetor Rp4.150.000 selama 10 tahun dengan jumlah setoran tiap bulannya Rp.200 ribu maka nasabah berhak mendapatkan hadiah hp Samsung J5 pro. Semakin lama dan semakin besar uang yang di tabung maka semakin besar juga hadiah yang bisa didapatkan seperti hadiah langsung berupa sepeda motor. Untuk mendapatkan hadiah sepeda motor anda harus menyetor uang diawal sebanyak Rp19.025.000 selama 10 tahun dengan setoran tiap bulannya Rp.700 ribu, dan jika nasabah menyetor diawal Rp 418.400.000 selama 10 tahun dengan setoran tiap bulannya sebesar Rp.14.600.000 maka anda berhak mendapatkan hadiah 1 unit mobil.

Jadi inti dari pemebrian hadiah pada tabungan berencana berhadiah dimana nasabah cukup menyetorkan uang diawal sebesar jumlah uang yang telah ditentukan dengan menabung tiap bulannya sebesar jumlah yang telah ditentukan oleh bank, semakin besar jumlah uang yang ditabung oleh nasabah semakin besar pula jumlah hadiah yang diterimanya. Dijelaskan oleh Rahmat Ali bahwa: 


\section{Ridwan Setiawan, Rahmawati dan Wahidin}

Pada proses penyetoran setiap bulannya pada program tabungan berencana hadiah ini nasabah bukan nyicil tapi menabung. ${ }^{7}$ Selain mendapatkan hadiahhadiah yang ditawarkan, nasabah yang membuka rekening di tabungan muamalat berencana berhadiah bebas biaya administrasi dan juga tetap akan mendapatkan keuntungan berupa bagi hasil setiap bulannya. Jika saldo tabungan semakin besar maka bagi hasil yang akan anda terima juga semakin besar.

\section{Implementasi Fatwa DSN-MUI NO: 86/ DSN-MUI/ XII/ 2012 Tentang} Hadiah Dalam Penghimpunan Dana Di Bank Muamalat KCP Parepare

Analisis kesesuaian fatwa Dewan Syariat Nasional-Majelis Ulama Indonesia (DSN-MUI) terkait hadiah yang terimplementasikan pada PT. Bank Muamalat KCP Parepare sebagai berikut.

a) Ketentuan Fatwa terkait Hadiah

1) Bentuk Hadiah

Hadiah yang diberikan oleh bank kepada nasabah merupakan hadiah atas balas jasa bank kepada nasabah atas penanaman dananya ke bank dan untuk menambah loyalitas nasabah. Bentuk hadiah yang diberikan bank untuk nasabah adalah bentuk barang dan bukan dalam bentuk uang. Program hadiah ini tidak melalui lagi proses pengundian tetapi hadiah langsung diberikan kepada nasabah sesuai dengan jumlah dana yang disetorkan ke bank. Dijelaskan oleh Abu Ali Farmadi bahwa:

Hadiah yang diberikan bank kepada nasabah merupakan ucapan terima kasih bank kepada nasabah dan hadiah yang kami berikan kepada nasabah merupakan dalam bentuk barang, bukan dalam bentuk uang. ${ }^{8}$

2) Hadiah Berupa Benda yang Berwujud

Pemberian hadiah yang diberikan bank berupa barang yang berwujud seperti smartphone, televisi, laptop, logam mulya, motor sampai dengan mobil. Untuk mendapatkan hadiah tersebut nasabah cukup menyimpan dananya ke bank lalu peserta dapat membawa pulang hadiah-hadiah yang mereka inginkan sesuai dari dana yang mereka simpan di bank. Sudah banyak nasabah yang mendapatkan hadiah berupa emas, handphone, motor, mobil, kulkas, TV, dan computer dari kedua program hadiah yaitu tabungan rencana berhadiah dan prima berhadiah. Dijelaskan oleh Rahmat Ali bahwa:

7 Rahmat Ali, pimpinan Bank Muamalat KCP Parepare, kec. Ujung kota Parepare, Sulsel, wawancara oleh penulis di Parepare, 1 Mei 2018.

8 Abu Ali Farmadi, costumer service Bank Muamalat KCP Parepare, kec. Ujung kota Parepare, Sulsel, wawancara oleh penulis di Parepare, 1 Mei 2018 
Hadiah yang telah kami sediakan itu berupa barang berwujud seperti smartphone, televisi, laptop, logam mulya, motor sampai dengan mobil. Jenis hadiah yang diberikan kepada nasabah sesuai proporsi dana yang disimpan oleh nasabah. Sudah ada nasabah yang mendapatkan hadiah berupa emas, handphone, motor, mobil, kulkas, TV, dan komputer. ${ }^{9}$

Salah satu nasabah yang sudah mendapatkan hadiah berupa satu unit lemari pendingin (kulkas), dengan syarat dimana nasabah tersebut mengendapkan dananya di Bank Muamalat KCP Parepare sejumlah Rp. 50.000.000 selama setahun. Seperti yang dijelaskan oleh Muh. Djunaidi bahwa:

Saya mendapatkan hadiah dari bank Muamalat KCP Parepare berupa kulkas, dimana saya menabung dengan mengendapkan dana saya selama setahun sebanyak Rp. 50.000.000.10

3) Hadiah Promosi yang Diberikan Mubah/Halal

Dalam pemberian hadiah dari bank kepada nasabah, hadiah tersebut merupakan pemberian dari bank langsung kepada nasbah, karena dana yang digunakan untuk membeli hadiah tersebut berasal dari cost of fund atau biaya dana yang dipakai bank untuk menarik nasabah untuk menabung dananya dibank dengan cara memberikan hadiah kepada nasabahnya yang menghimpun dananya. Jadi asal-usul dari kejelasan hadiah tersebut sudah jelas, maka status dari hadiah tersebut halal dan bukan hasil dari praktek suap, pencucian uang, pencurian dan sebagainya. Dijelaskan oleh Rahmat Ali bahwa:

Hadiah yang diberikan kepada nasabah itu berasal dari cost of fund atau biaya dana yang dipakai bank untuk menarik nasabah untuk menabung dananya dibank dengan cara memberikan hadiah kepada nasabahnya yang menghimpun dananya, jadi hadiah tersebut halal karena bukan berasal dari hasil praktek suap, pencucian uang dan pencurian. ${ }^{11}$

4) Hadiah Promosi Milik LKS, Bukan Milik Nasabah

Di dalam penghimpunan dana dibank ada yang dinamakan cost of fund dimana merupakan biaya yang harus dikeluarkan oleh bank untuk setiap dana yang berhasil dihimpun dari berbagi sumber sebelum dikurangi dengan likuiditas wajib minimum yang harus dipelihara oleh bank. Bahwa untuk memperoleh dana dari sumbernya, bank harus mengeluarkan sejumlah biaya, dimana biaya tersebut merupakan harga rill dari sumber dana yang dapat dihimpun bank. Dengan diketahuinya jumlah biaya dana sesungguhnya yang dikeluarkan bank

9 Rahmat Ali, pimpinan Bank Muamalat KCP Parepare, kec. Ujung kota Parepare, Sulsel, wawancara oleh penulis di Parepare, 1 Mei 2018

${ }_{10}$ Muh. Djunaidi, Nasabah Bank Muamalat KCP Parepare, Lapadde Mas, Kec. Ujung Kota Parepare, Sulsel, Wawancara oleh penulis di Parepare, 6 Juli 2018

11 Rahmat Ali, pimpinan Bank Muamalat KCP Parepare, kec. Ujung kota Parepare, Sulsel, wawancara oleh penulis di Parepare, 1 Mei 2018 


\section{Ridwan Setiawan, Rahmawati dan Wahidin}

untuk sumber dana, maka bank akan memperoleh kepastian laba rugi dalam pemasaran dana dalam bentuk kredit yang dilakukan oleh bank yang bersangkutan. Jadi sumber dana yang dipakai bank untuk membeli hadiah berasal dari cost of fund, dimana cost of fund ini merupakan biaya dana yang dipakai bank untuk menarik nasabah untuk menabung dananya dibank dengan cara memberikan hadiah kepada nasabahnya yang menghimpun dananya dengan persyaratan yang telah diatur oleh bank itu sendiri. Dijelaskan oleh Rahmat Ali bahwa:

Dana yang digunakan untuk membeli hadiah tersebut dari cost of fund atau biaya dana yang dipakai bank untuk menarik nasabah untuk menabung dananya dibank dengan cara memberikan hadiah kepada nasabahnya yang menghimpun dananya. ${ }^{12}$

5) Penggunaan Akad

Dalam pemberian hadiah dibank Muamalat KCP Parepare hadiah akan diserahkan setelah akad itu sudah disetujui oleh kedua belah pihak yaitu bank dan nasabah lalu akan diserahkan hadiahnya karena akad yang digunakan dalam produk tabungan berhadiah ini bukan menggunakan akad wadiah melainkan pihak bank menggunakan akad mudharabah, jadi hadaih bisa diberikan setelah terjadinya akad tersebut, dan pada akad mudharabah selain nasabah mendapatkan hadiah, nasabah juga mendapatkan bagi hasil, semakin banyak dana yang dihimpun oleh nasabah semakin banyak pula margin yang didapatkan dari bagi hasil tersebut dan dan bank membebaskan biaya administrasi untuk nasabah penghimpun.dijelaskan oleh Abu Ali Farmadi bahwa:

Tabungan berhadiah ini menggunakan akad mud\}a>rabah, dimana selain mendapatkan hadiah nasabah juga akan mendapatkan bagi hasil dan bebas biaya administrasi. ${ }^{13}$

6) Syarat-Syarat yang Tidak Menjurus ke Praktek Riba

Dalam suatu program pemberian hadiah bank perlu memberikan syarat-syarat dan ketentuan untuk memberikan suatau hadiah agar jelas dan dalam pemberian syarat pihak bank harus memperhatikan aspek hukumnya baik itu hukum positif maupun hukum Islamnya. Jadi Bank Muamalat KCP Parepare mengeluarkan syarat dalam mengikuti program tabungan berhadiah sebagai berikut:

a) Nasabah harus nasabah bank Muamalat

b) Membuka tabungan

c) Sumber dananya harus jelas

d) Bukan hasil pencucian uang

12 Rahmat Ali, pimpinan Bank Muamalat KCP Parepare, kec. Ujung kota Parepare, Sulsel, wawancara oleh penulis di Parepare, 1 Mei 2018

13 Abu Ali Farmadi, costumer service Bank Muamalat KCP Parepare, kec. Ujung kota Parepare, Sulsel, wawancara oleh penulis di Parepare, 1 Mei 2018 
e) Bukan hasil penipuan dan sebagainya

f) Dana harus sepenuhnya milik nasabah

Untuk program tabungan prima berhadiah nasabah hanya cukup menghimpun dananya hanya satu kali sejumlah yang telah ditetapkan oleh bank dan akan mendapatkan hadiah yang dinginkannya sesuai porsi dana yang nasabah setorkan dibank. Untuk program tabungan rencana berhadiah nasabah harus menyetorkan dananya diawal dengan jumlah yang telah ditetapkan bank lalu nasabah harus menabung selama jangka waktu yang disepakati nasbah dan bank, untuk bentuk hadiah yang diterima oleh nasabah sesuai porsi dana yang disetorkan dibank. Selain nasabah mendapatkan hadiah, nasabah juga akan mendapatkan bagi hasil dan nasabah mendapatkan asuransi kesehatan dan premi dari asuransi tersebut dibayarkan oleh bank. Seperti yang dijelaskan oleh Rahmat Ali bahwa:

Syarat yang kami berikan kepada nasabah ketika ingin mengikuti program hadiah ini, nasabah harus nasabah bank Muamalat, membuka tabungan, sumber dananya jelas bukan dari hasil pencucian uang, bukan hasil penipuan, dan tentunya dana harus milik nasabah. Kalau untuk tabungan rencana hadiah nasabah menabung bukan nyicil, pada prima berhadiah nasabah cukup mengendapkan dananya sekali saja. ${ }^{14}$

7) Pengembalian Hadiah

Setiap dalam pelaksanaan program berhadiah bank dalam menarik nasabah untuk menyimpan dananya dibank, akan ada yang namanya syarat yang diberikan untuk mendapatkan hadiah tersebut, dan adapula nasabah yang ingkar terhadap syarat-syarat yang diberikan oleh bank, di Bank Muamalat KCP Parepare merujuk kepada fatwa DSN-MUI NO 86/DSN-MUI/ XII / 2012 Tentang Hadiah Dalam Penghimpunan Dana Lembaga Keuangan Syariah, bank dalam fatwa berhak mengatur. Jadi status hadiah yang diberikan nasabah hanya mempunyai hak guna pakai dari barang tersebut, jadi nasabah berhak memanfaatkan hadiah tersebut sampai jangka waktu pengendapan dana berakhir, dimana jika nasabah ingkar dari jangka waktu yang telah disepakati dan syarat-syarat yang lainnya yang telah diberikan dari bank maka bank dapat menarik kembali hadiah yang diberikan atau nasabah membayar biaya penggantian hadiahnya. Ketika nasabah tidak ingkar terhadap syarat-syarat dan menyelesaikan program tabungan pemberian hadiah tersebut maka hadiah sepenuhnya milik nasabah. Dijelaskan oleh Rahmat Ali bahwa:

Kan kalau tabungan prima berhadiah ada waktu pengendapan dana, nabung sekian juta selama 12 bulan dan baru 10 bulan dilanggar, kalau tabungan rencana

${ }^{14}$ Rahmat Ali, pimpinan Bank Muamalat KCP Parepare, kec. Ujung kota Parepare, Sulsel, wawancara oleh penulis di Parepare, 1 Mei 2018 


\section{Ridwan Setiawan, Rahmawati dan Wahidin}

berhadiah nabung 10 tahun tapi baru 9 tahun berhenti kan sudah melanggar akadnya diawal, jadi disitulah bank berhak menarik hadiah tersebut. ${ }^{15}$

8) Kebijakan Pemberian Hadiah

Dewan Pengawasan Syariah merupakan pihak terafiliasi dan bagian dari Bank. DPS adalah dewan yang melakukan pengawasan terhadap Prinsip Syariah yang dipakai dalam menjalankan kegiatan usaha Bank Syariah secara independen. Setiap Bank Umum Syariah atau Bank Konvensional yang memiliki Unit Usaha Syariah harus memiliki setidaknya 2-5 orang sebagai anggota Dewan Pengawasan Syariah. Sedangkan untuk Bank Pengkreditan Rakyat Syariah setidaknya memiliki 1-3 orang anggota DPS. Jika anggota DPS di setiap lembaga keuangan syariah memiliki lebih dari satu anggota maka salah satu dari anggota tersebut harus menjadi ketua DPS dilembaga Keuanngan Syariah tersebut. Persyaratan utama bagi anggota Dewan Pengawas Syariah adalah mereka harus memiliki kemampuan di bidang Hukum Muamalah, Hukum Ekonomi dan Perbankan.

a) Tugas, Wewenang dan Tanggungjawab Dewan Pengawas Syariah(DPS) antara lain:

- Memastikan dan mengawasi kesesuaian kegiatan operasional Bank terhadap fatwa yang telah ditetapkan oleh DSN-MUI.

- Menilai aspek syariah terhadap pedoman operasional. Dan produk yang dikeluarkan Bank.

- Memberikan opini dari aspek syariah terhadap pelaksanaan operasional Bank secara keseluruhan dan laporan publikasi Bank.

- Mengkaji produk dan jasa baru yang belum ada fatwa untuk dimintakan fatwa kepada DSN-MUI.

- Menyampaikan hasil pengawasan syariah sekurang-kurangnya setiap 6 bulan kepada Direksi, Komisaris, DSN-MUI dan Bank Indonesia.

Jika dilihat dari tugas dan wewenang dari DPS, maka bank syariah dalam menetapkan kebijakan yang dikeluarkan untuk program pemberian hadiah sudah melalui persetujuan dari pihak DPS itu sendiri. Dijelaskan oleh Rahmat Ali bahwa:

Kita tidak bisa mengeluarkan produk kalau tidak ada persetujuan dari Dewan Pengawas Syariah (DPS) dan rujukan program berhadiah ini adalah fatwa DSNMUI NO 86 tentang pemberian hadiah pada penghimpunan dana. ${ }^{16}$

15 Rahmat Ali, pimpinan Bank Muamalat KCP Parepare, kec. Ujung kota Parepare, Sulsel, wawancara oleh penulis di Parepare, 1 Mei 2018

16 Rahmat Ali, pimpinan Bank Muamalat KCP Parepare, kec. Ujung kota Parepare, Sulsel, wawancara oleh penulis di Parepare, 1 Mei 2018 
9) Pengawasan Otoritas Terkait

Melihat perkembangan bank syariah selama ini, prinsip syariah yang menjadi landasan utama bank syariah dalam menjalankan tugasnya belum dapat diterapkan dan ditegakkan secara optimal terutama dalam hal apabila terjadi sengketa antara para pihak, bank syariah dan nasabahnya, Oleh karena itu perlu ada lembaga pengawasan terhadap lembaga-lembaga keuangan syariah agar dapat meminimalisir terjadinya kecurangan-kecurangan dari beberapa pihak yang nantinya akan merugikan masyarakat. Jadi Bank Indonesia yang mengamanatkan dibentuknya lembaga pengawas sektor jasa keuangan independen yaitu Otoritas Jasa Keuangan (OJK) yang mencakup pengawasan perbankan, pasar modal, industri keuangan non bank, serta badan-badan lain yang menyelenggarakan pengelolaan dana masyarakat.

OJK dalam menjalankan tugasnya sebagai pengawas perbankan syariah ternyata tidak melakukan pengawasan tehadap semua aktivitas lembaga syariah itu, melainkan ada beberapa aspek yang secara khusus diawasi oleh lembaga lain, dalam hal ini adalah DPS (Dewan Pengawas Syariah). DPS adalah bagian dari Lembaga Keuangan Syariah, yang bersangkutan yang penempatannya atas persetujuan Dewan Syariah Nasional (DSN). Jadi perbankan syariah memiliki dua otoritas yang mengawasi kegiatan operasional yang saling berhubungan satu sama lain. Dijelaskan oleh Rahmat Ali bahwa:

OJK sudah memberikan ijin produk, dari sisi syariahnya dari DPS yang sesuai dengan fatwa, dan dari OJK sudah ada petisinya. ${ }^{17}$

Untuk melaksanakan tugas pengaturan dan pengawasan di kegiatan jasa keuangan sektor perbankan, OJK mempunyai wewenang:

- Pengaturan dan pengawasan di lembaga perbankan meliputi :

- Perizinan untuk pendirian bank, pembukaan kantor bank, anggaran dasar, rencana kerja, kepemilikan, kepengurusan dan sumber daya manusia, merger,konsolidasi dan akuisisi bank, serta pencabutan izin usaha bank.

- Kegiatan usaha bank, antara lain sumber dana, penyediaan dana, produk hibridasi dan aktiva di bidang jasa

- Pengaturan dan pengawasan mengenai kesehatan bank yang meliputi :

- Likuiditas, rentabilitas, solvabilitas,kualitas asset, rasio kecukupan modal minimum, batas maksimum pemberian kredit, rasio pinjaman terhadap simpanan dan pencadangan bank.

- Laporan bank yang terkait dengan kesehatan dan kinerja bank

- Sistem informasi debitur

${ }^{17}$ Rahmat Ali, pimpinan Bank Muamalat KCP Parepare, kec. Ujung kota Parepare, Sulsel, wawancara oleh penulis di Parepare, 1 Mei 2018. 


\title{
M. Ridwan Setiawan, Rahmawati dan Wahidin
}

\author{
- Pengujian kredit \\ - Standar akuntansi perbankan
}

b) Ketentuan Terkait Cara Penentuan Penerima Hadiah

Dalam menentukan penerima hadiah, bank akan memberikannya kepada nasabah yang telah memenuhi syarat dan ketentuan penerimaan hadiah yang telah ditentukan oleh bank, bukan dikarenakan nasabah melakukan risywah atau menyogok pihak bank agar bank memberikan hadiah tersebut dan tidak ada syarat-syarat yang menjurus kepraktik riba terselubung.

Ketentuan tentang kewajiban untuk terhindar dari mai $>$ sir, riba>, dan ga>rarserta 'aql al-ma>l bil bhati>l.Mai $>$ simerupakan sesuatu yang dilarang oleh Islam yang mana maysir merupakan perjudian. Maysir dalam undian berhadiah dapat terjadi ketika peserta membayar iuran, undian yang seperti ini dilarang sekalipun iurannya dalam jumlah sedikit. Hal yang seperti ini adalah gharar yang nyata, di mana peserta membayar iuran yang kemungkinan ia mendapatkan hadiah sehingga berlaba atau ia tidak mendapat apa-apa sehingga ia rugi, maka undian ini termasuk maysir.

Bank Muamalat dalam peraktik pemberian hadiahnya melakukan pemberian hadiah secara langsung setelah nasabah menyimpan dananya dengan cara mengendapkan dananya selama waktu yang telah ditetapkan oleh bank yang disetujui oleh kedua belah pihak yaitu bank dan nasabah.

c) Ketentuan Terkait Hadiah Dalam Simpanan Dana Pihak Ketiga (DPK)

Fatwa DSN MUI nomor 86/DSNMUI/XII/2012 tentang hadiah dalam penghimpunan dana lembaga keuangan syariah memberi ketentuan terkait hadiah dalam simpanan DPK lembaga keuangan syariah boleh memberikan hadiah atas simpanan nasabah dengan syarat sesuai fatwa DSN-MUI nomor 01/DSNMUI/IV/2000 tentang giro, dan nomor 02/DSNMUI/IV/2000 tentang tabungan. Selain itu adanya larangan menjurus kepada praktik riba, dan tidak boleh menjadi kelaziman (kebiasaan, 'urf).

Bank Muamalat KCP Parepare menjalankan program hadiah pada produk tabungan, sehingga pembahasan terbatas pada fatwa DSN MUI nomor 02/DSNMUI/IV/2000 tentang tabungan. Fatwa DSN MUI nomor 02/DSN-MUI/IV/2000 tentang tabungan memutuskan bahwa tabungan ada dua macam yakni yang dilarang oleh syariah yaitu tabungan yang perhitungannya dengan bunga, dan tabungan yang sesuai syariah yaitu tabungan dengan prinsip mud\}arabah dan wadiah.

1) Ketentuan yang dikeluarkan oleh MUI tentang tabungan mudharabah meliputi:

- LKS sebagai mudharib dan nasabah sebagai shohibul maal.

- LKS dapat melakukan berbagai macam usaha dengan catatan sesuai dengan syariah.

- Modal harus dinyatakan dalam jumlah tunai bukan sebagai piutang.

- Pembagian nisbah harus jelas dan telah dijelaskan di awal kontrak.

- LKS dilarang untuk mengurangi nisbah tanpa adanya kesepakatan dari nasabah. 
2) Ketentuan tabungan wadi'ah yang dikeluarkan oleh MUI adalah sebagai berikut:

- Bersifat simpanan.

- Simpanan bisa diambil kapan saja dengan adanya kesepakatan.

- Tidak adanya imbalan yang dipersyaratkan kecuali dalam bentuk pemberian sukarela.

Bank Muamalat dalam menjalankan program penerimaan hadiah menggunakan akad mudharabah muthlaqah.Dalam mud\}a>rabah mut $\}$ laqah, nasabah yang meyimpan dananya di bank syariah tidak memberikan pembatasan bagi bank syariah dalam menggunakan dana yang disimpannya. Bank Syariah bebas untuk menetapkan akad seperti apa yang akan nantinya akan dipakai ketika menyalurkan pembiayaan, kepada siapa pembiayaan itu diberikan, usaha seperti apa yang harus dibiayai dan lain-lain. Jadi prinsip mud $\} a>$ rabah mut $\}$ laqablebih memberikan keleluasaan bagi bank. Dijelaskan oleh Rahmat Ali bahwa:

Akad yang digunakan dalam program pemberian hadiah ini yaitu akad mudharabah mutlaqah, dimana bank bebas menetapkan penggunaan dana nasabah dan tanpa melupakan prinsip syariahnya. Selain nasabah mendapatkan hadiah, nasabah juga tetap mendapatkan bagi hasil dan bebas biaya administrasi. ${ }^{18}$

Urf atau kelaziman yang dilarang oleh DSN MUI dalam fatwa hadiah menurut Pakar ekonomi dan keuangan syariah bapak Suherman Rosyidi menyatakan bahwasanya 'Urf atau kelaziman yang dilarang oleh DSN MUI dalam fatwa hadiah bertujuan untuk menghindari adanya berubahnya niat seseorang dari niat menabung atau menempatkan dana beralih menjadi ingin mendapatkan hadiah. Hal ini bisa dikatakan adanya sebab adanya niat yang berubah dari nasabah dari menabung menjadi keinginan untuk mendapatkan sesuatu dengan tanpa adanya usaha. ${ }^{19}$ Pada pelaksanaan program tabungan berhadiah pada bank Muamalat KCP Parepare bertujuan hanya untuk menarik nasabah untuk menyimpan dananya dibank dan agar nasabah loyal terhadap bank, bank Muamalat melaksanakan program ini berlaku dalam 6 bulan dan akan tetapi program ini sudah beberapa kali diperpanjang, alasan bank Muamalat memperpanjang programnya bertujuan untuk mendiversifikasi produk dan sebagai strategi bisnis untuk menarik suatu nasabah, dalam perpanjangan program tabungan berhadiah ini mengalami beberapa kali perubahan syarat dan jenis hadiah. Dijelaskan oleh Rahmat Ali bahwa:

${ }^{18}$ Rahmat Ali, pimpinan Bank Muamalat KCP Parepare, kec. Ujung kota Parepare, Sulsel, wawancara oleh penulis di Parepare, 1 Mei 2018.

${ }^{19}$ Khoirun Nisak, "Fatwa DSN MUI Nomor 86/DSN-MUI/XII/2012 Tentang Hadiah Dalam Penghimpunan Dana Lembaga Keuangan Syariah: Implementasi Pada BMT Ugt Sidogiri Pasuruan,” jurnal ekonomi syariah teori dan terapan vol. 4 no. 5, 2017), h. 353-366. 


\section{Ridwan Setiawan, Rahmawati dan Wahidin}

Program hadiah ini merupakan program khusus dari bank Muamalat, program ini akan berakhir dibulan 6 tahun 2018 dan program ini bisa saja akan mengalami perpanjang lagi seperti tahun-tahun sebelumnya.Alasan program ini diperpanjang sebagai diversifikasi produk dan sebagai strategi bisnis. ${ }^{20}$

Jika program ini berakhir, nasabah yang mengikuti program ini tetap melanjutkan program hadiah ini, akan tetapi bank tidak akan menerima lagi nasabah baru yang ingin mengikuti program tersebut.

\section{Kesimpulan}

Sistem pemberian hadiah pada Bank Muamalat KCP Parepare memiliki dua macam tabungan yang menawarkan pemberian hadiah yaitu tabungan prima berhadiah dan tabungan rencana berhadiah, dan kedua memiliki perbedaan sistem dalam operasionalnya :

Tabungan prima berhadiahnasabah menyetorkan uangnya sebesar jumlah yang telah ditetapkan oleh bank selama jangka waktu yang telah ditentukan oleh bank, semakin besar dana yang nasabah tabungkan semakin besar pula hadiah yang diterima oleh nasabah. Selain mendapatkan hadiah-hadiah yang ditawarkan, nasabah yang membuka rekening di tabungan muamalat prima berhadiah juga bebas biaya administrasi dan tetap akan mendapatkan keuntungan berupa bagi hasil setiap bulannya dan jika saldo tabungan semakin besar maka bagi hasil yang akan anda terima juga semakin besar.

Tabungan rencana berhadiah dimana nasabah cukup menyetorkan uang diawal sebesar jumlah uang yang telah ditentukan dengan menabung tiap bulannya sebesar jumlah yang telah ditentukan oleh bank, semakin besar jumlah uang yang ditabung oleh nasabah semakin besar pula jumlah hadiah yang diterimanya. Selain mendapatkan hadiah-hadiah yang ditawarkan, nasabah yang membuka rekening di tabungan muamalat berencana berhadiah bebas biaya administrasi dan juga tetap akan mendapatkan keuntungan berupa bagi hasil setiap bulannya. Jika saldo tabungan semakin besar maka bagi hasil yang akan anda terima juga semakin besar.

Hasil pengimplementasian Fatwa DSN-MUI No.86/DSN-MUI/XII/2012 tentang penerimaan hadiah dalam penghimpunan dana lembaga keuangan syariah sebagai berikut.

Pada fatwa ketentuan terkait hadiah semua poin sudah sesuai dengan fatwa yang telah ditetapkan oleh Dewan Syariah Nasional-Majelis Ulama Indonesia begitupun ketentuan yang terkait tentang cara penentuan penerima hadiah akan tetapi pada ketentuan terkait hadiah dalam simpanan Dana Pihak Ketiga (DPK) tidak semua sesuai dengan fatwa yang dikeluarkan oleh Dewan Syariah Nasional-Majelis Ulama Indonesia tentang penerimaan hadiah dalam penghimpunan dana lembaga keuangan syariah terkhusus pada point ketiga yaitu tidak boleh menjadi kelaziman (kebiasaan, 'urf), dimana dijelaskan oleh Pakar ekonomi dan keuangan syariah bapak Suherman Rosyidi menyatakan bahwasanya 'urf atau kelaziman

${ }^{20}$ Rahmat Ali, pimpinan Bank Muamalat KCP Parepare, kec. Ujung kota Parepare, Sulsel, wawancara oleh penulis di Parepare, 1 Mei 2018. 
yang dilarang oleh DSN-MUI dalam fatwa hadiah bertujuan untuk menghindari adanya berubahnya niat seseorang dari niat menabung atau menempatkan dana beralih menjadi ingin mendapatkan hadiah. Hal ini bisa dikatakan adanya sebab adanya niat yang berubah dari nasabah, niat dari menabung menjadi keinginan untuk mendapatkan sesuatu dengan tanpa adanya usaha. Pada Bank Muamalat Parepare dalam menjalankan program tabungan berhadiahnya dilaksanakan selama 6 bulan akan tetapi program tersebut sudah beberapa kali diperpanjang dan akan menjadi kebiasaan yang dilakukan oleh bank dan hal itulah yang dilarang oleh Fatwa DSN-MUI No.86/DSN-MUI/XII/2012 tentang penerimaan hadiah dalam penghimpunan dana lembaga keuangan syariah.

\section{Daftar Pustaka}

\section{Buku}

Al Bukhari, Imam Abdullah Muhammad bin Ismail, Fikih Ekonomi Syariah ,Jakarta: Rajawali Press, 2017.

Antonio, Muhammad Syafi'i. 2001.Bank Syariah Dari Teori Ke Praktek, Jakarta: Gema Insani Press.

Barlinti, Yeni Salman. 2010. Kedudukan Fatwa Dewan Syariah Nasional dalam Sistem Hukum Nasional di Indonesia, Jakarta: Badan Litbang dan Diklat Kementrian Agama.

Basrowi \& Suwandi. ,2009.Memahami Penelitian KualitatifJakarta: PT. Asdi Mahasatya.

Departemen Agama RI. 2002.Al-Qur'an Terjemahnya, Jakarta: CV Darus Sunnah.

Departemen Agama RI. 2002. Al-Qur'an Terjemahnya, Semarang: PT. Karya Toha Putra Semarang.

Departemen Pendidikan Nasional .2005.Kamus Besar Bahasa Indonesia Edisi Ke-3Jakarta: Balai Pustaka.

Hamidi, M. Luthfi. 2003. Jejak-jejak Ekonomi Syariah , Jakarta: Senayan Abadi Publishing.

Karim, Helmi. 2002.Fiqih Muamalah, Jakarta: PT. Raja Grafindo Persada, Cetakan Ketiga.

Kotler, Philip. 2005.Manajemen Pemasaran, Jakarta: PT. Indeks.

Mardani. 2005.Ushul Fiqh, Jakarta: PT Raja Grafindo Persada.

Muhammad. 2008.Metodologi Penelitian Ekonomi Islam Pendekatan Kuantitatif, Jakarta : PT Raja Grafind Persada.

Muttaqiyah, Matsna. 2014. Analisis Penerapan Fatwa Nomor 86/DSN-MUI/XII/2012 Tentang Hadiah Dalam Penghimpunan Dana Lembaga Kenangan Syariah di KJKS BINAMA Semarang, UIN Walisongo, Semarang.

Noor, Dr Juliansyah, S.E, M.M. ,Metodologi Penelitian : Skripsi, Tesis, Disertasi, dan Karya Ilmiah (Jakarta: Charisma Putra Kencana) 


\section{Ridwan Setiawan, Rahmawati dan Wahidin}

Rozalinda. 2017. Fikih Ekonomi Syariah , Jakarta: Rajawali Press.

Siregar, Sofyan. 2010.Statistik Deskriptif Untuk Penelitian: Dilengkapi Perbitungan Manual Dan Aplikasi SPSS Versi Versi 17, Edisi I (Cet, 1; Jakarta Rajawali Pers)

Suhendi, Hendi. 2005.Fiqih Muamalah, (Jakarta: PT. Raja Grafindo Persada.

Usman, Nurdin.2002.Konteks Implementasi Berbasis Hukum.

Purnomo ,Rizky.2015.Konsep Hadiah Dalam Akad Wadi'ah Di Bank Syariah Perspektif Fatwa DSN-MUI No.86/DSN-MUI/XII/2012), UIN Sunan Kalijaga, Yogyakarta.

Sjahdeini. Sutan Remy. 2014. Perbankan Syariah, Jakarta: PT Adhitya Andrebina Agung.

Sugiyono. 2010.Metode Penelitian Pendidikan Pendekatan Kuantitatif, Kualitatif, Dan R \& D, Bandung: Alfabeta, Cet Ke-10

Sutopo , Ariesto Hadi dan Adrianus Arief. 2010. Terampil Mengolah Data Kualitatif Dengan NVIVO, Jakarta: Prenada Media Group.

Ustani, Trisadini P. dan Abd. Shomad. 2015. Transaksi Bank Syariah. Jakarta: Bumi Aksara.

Warita ,Tri.2011.Pemberian Hadiah Pada Program Tabungan Muamalat Berbagi Rejeki Menurut Perspektif Ekonomi Islam (Study Pada PT. Bank. Muamalat Tbk Cabang Pekanbaru), UIN Sultan Syarif Kasim, Riau.

\section{Hadis:}

HR. Bukhari dalam Al-Adab Al-Mufrod, no. 594. Hadits ini dihasankan oleh Syaikh AlAlbani dalam Al-Irwa', no. 1601.

\section{Wesbite}

Fatwa DSN-MUI No. 86/DSN-MUI/XII/2012. 2018.tentang Hadiah dalam penghimpunan dana lembaga keuangan syariah.https://tafsirq.com/fatwa/dsn-mui/hadiah-dalampenghimpunan-dana-lembaga-keuangan-syariah (diakses pada tanggal 11 april)

http://id.m.Wikipedia.org / wiki/produk (20 April 2017)

https://id.m.wikipedia.org/wiki/Fatwa (21 Mei 2017)

http://www.kbbi.co.id (21 Mei 2017)

http://www.bankmuamalat.co.id/produk-layanan-consumer (07 Maret 2018)

http://www.bankmuamalat.co.id/visi misi (21 Mei 2018)

https://www.scribd.com/doc/84097240/Gambaran-Umum-Bank-Muamalat-Indonesia (21 Mei 2018) 